\section{COST-EFFECTIVENESS ANALYSIS ON THE USE OF PARENTERAL NUTRITION WITH D10-CA GLUCONATE AND D5 1/4NS IN NORMAL-WEIGHT NEONATES WITH RESPIRATORY DISTRESS SYNDROME}

\author{
FITRIA NINGSIH ${ }^{1,2}$, RANI SAURIASARI ${ }^{1 *}$, AGUSDINI BANUN SAPTANINGSIH ${ }^{3}$ \\ ${ }^{1}$ Department of Pharmacy, Faculty of Pharmacy, Universitas Indonesia, Depok, Indonesia. ${ }^{2}$ Department of Apothecary, Kambang \\ General Hospital, Jambi, Indonesia. ${ }^{3}$ Directorate General of Pharmaceutical Services and Medical Devices, Ministry of Health, Indonesia. \\ Email: rani@farmasi.ui.ac.id
}

Received: 21st April 2017, Revised and Accepted: 18th August 2017

\title{
ABSTRACT
}

Objectives: This retrospective cohort study aimed to compare the cost-effectiveness of using D10-CaGluconate and D5 1/4NS preparations in normalweight neonatal patients with Respiratory Distress Syndrome (RDS) in Kambang General Hospital, Jambi, Indonesia.

Methods: The research was conducted from September 2014 to June 2015. The study participants were divided into two groups; D10-CaGluconate was administered to 40 patients and D5 1/4NS to 43 patients. Effectiveness was assessed based on the changes in the physical examination results, average weight gain (28.48 and $23.49 \mathrm{~g} /$ day), blood glucose levels $(26.73$ and $26.42 \mathrm{mg} / \mathrm{dL})$, respiratory rate $(-12.35 \mathrm{breaths} / \mathrm{minute}$ and -7.77 breaths/minute), pulse frequency $\left(-10.98\right.$ and $-8.07 \pm$ ), and body temperature $\left(0.013^{\circ} \mathrm{C}\right.$ and $\left.0.012^{\circ} \mathrm{C}\right)$ of the patients in the D10-CaGluconate and D5 1/4NS groups, respectively.

Results: The average direct medical costs of using D10-CaGluconate and D5 1/4NS were 458,290 IDR and 408,347 IDR, respectively. The average costeffectiveness ratio value of total direct medical costs for D10-CaGluconate preparation was 35,207,467 IDR while that for D5 1/4NS was 33,958,602 IDR. The direct medical cost of the incremental cost-effectiveness ratio mean value of the D5 1/4NS preparation that compared to the D10-CaGluconate preparation was 10,017,210 IDR.

Conclusions: The parenteral nutrition preparation of D10-CaGluconate is more cost-effective than that of D5 1/4NS.

Keywords: D10-CaGluconate, D5 1/4NS, Effectiveness, Direct medical costs, Incremental cost-effectiveness ratio.

(C) 2017 The Authors. Published by Innovare Academic Sciences Pvt Ltd. This is an open accessarticle under the CC BY license (http://creativecommons. org/licenses/by/4. 0/) DOI: http://dx.doi.org/10.22159/ijap.2017.v9s1.36_42

\section{INTRODUCTION}

Health is one of the basic human rights. The 1945 Constitution of the Republic of Indonesia assures optimal access to health services for every Indonesian, including those with financial disadvantages. Indonesia is committed to achieving the Millennium Development Goals (MDGs) target from 2000 to 2015 . One of the strategically planned programs designed by the Ministry of Health for the period 2010-2014 to achieve the MDGs is the National Health Insurance Program [1]. The health systems have established three goals: Creating fairness in health-care financial management, improving health status, and enhancing the responsiveness of medical services [2]. Under the goal of health-care financial management, it must be assured that the entire health fund is optimally distributed to ensure adequate and optimal health-care services for all citizens. This means that the government must develop an efficient health financing system to fulfill all the health needs of each citizen [2]. Increasing the cost-effectiveness of drugs would improve the efficiency of the national health financing system at the Government level as well as at local levels, such as in hospitals. Pharmacoeconomics is the study of the economic aspect of drugs, including the costeffectiveness [1]. The results of such pharmacoeconomic studies can be used for determining and developing the most efficient method of using limited health resources.

The Kambang General Hospital is a private hospital located in Jambi City, Jambi Provinces, Indonesia. It is a referral hospital, which accepts and treats neonatal emergency patients referred by other hospitals. This hospital has continuous positive airway pressure facility, which is used for treating neonates in emergencies, especially in the case of respiratory system disorder (RDS). The number of neonatal patients with a diagnosis of RDS is the highest case in the Kambang Hospital.
Since 2013, the Kambang Hospital has used parenteral nutrition preparations to treat RDS patient. Two types of preparations are used: D10-CaGluconate and D5 1/4NS. These two products are the treatments of choice for normal-weight neonatal patients with RDS. D10-CaGluconate $(1000 \mathrm{~mL})$ consists of $100 \mathrm{~g}$ Dextrosa and 6-8 mL/kg/ weight CaGluconate. On the other hand, $1000 \mathrm{~mL}$ of D5 1/4NS consists $\mathrm{Na}(38.5 \mathrm{mEq}), \mathrm{Cl}(38.5 \mathrm{mEq})$, with composition of dextrose $50 \mathrm{~g}$ and $\mathrm{NaCl} 2.25$ g (MIMS, 2013). D10-Gluconas increases the blood glucose level rapidly; however, it involves a higher risk of hyperglycemia. It can also lead to hyperxemia; therefore, calcium gluconas is administered simultaneously. In contrast, D5 1/4NS increases blood glucose gradually, causing the low risk of hyperglycemia. To the best of our knowledge, no research has been done to assess the cost-effectiveness of these two preparations. In addition, the cost-effectiveness analysis at Kambang Hospital is important due to a large quantity of these preparations. Therefore, we planned this study with the aim of determining the cost effectiveness of these parenteral nutrition preparations in neonatal patients, the treatment duration, and the direct medical cost involved. We believe that this study will be useful in developing the protocol, establishing the standard treatment cost, and assessing the costeffectiveness of treatment in Kambang Hospital. This will enable the provision of cost-effective parenteral nutrition for neonatal health services in the JKN era.

\section{METHODS}

This retrospective cohort study was conducted in the Kambang Hospital in Jambi city in 2015. We used secondary data from the medical records of normal-weight neonatal patients who were administered the parenteral nutrition preparations D10-CaGluconate and D5 1/4NS in Kambang Hospital. The total sampling technique was used. 371 patients 
were treated in 2013 and 448 in 2014; this added up to 819 patients who were treated at the hospital from January 2013 to December 2014. Normal-weight neonatal patients who were hospitalized at the Kambang Hospital for RDS and were administered parenteral nutrition preparations D10-CaGluconate and D5 1/4NS were included in the study. Neonatal patients, who did not recover, deteriorated, died during treatment, were discharged against medical advice from the Kambang Hospital, experienced hyperglycemia, were low birth weight neonates, or had incomplete medical records were excluded.

The parenteral nutrition preparations D10-CaGluconate and D5 1/4NS were the independent variables. Cost and clinical effectiveness parameters of weight gain, blood glucose level, respiratory rate, pulse frequency, and body temperature were the dependent variables. The confounding variables were age, gestational age, sex, comorbidities, socioeconomic status, and insurances. Patients' data regarding age, condition at birth, medical history regarding illnesses, and other observations who used parental nutrition were collected from the medical records of the Kambang Hospital. The data were analyzed using univariate analysis to obtain the frequency distribution and proportions of all the variables such as the medical cost, clinical effectiveness, age, sex, comorbidities, socioeconomic status, and insurances. Chi-square bivariate analysis was used to study the relationship between the variables and the effects of each independent and confounding variable on the dependent variables.

\section{RESULTS}

As shown in the Table 1, the majority of patients treated in the perinatology room at the Kambang Hospital, Jambi comprised neonates aged 1-14 days; $97.5 \%$ were under treatment with preparation A (D10-CaGluconate), and $86 \%$ with preparation B (D5 1/4NS) with $83.5 \%$ patients were treated with both preparation $\mathrm{A}$ and $\mathrm{B}$. There were no marked sex differences in the treatment groups. Group A had an equal proportion of boy and girl patients (50\%); however, in Group B, the proportion of boys was greater $(55.8 \%)$ than that of girls (44.2\%). Majority of the neonates (55\%) in Group A had a gestation age $\geq 36$ weeks. In addition, most patients in Group A were born at full gestational age and had a normal birth weight, followed by those born at a gestational age of 32-35 months (37.5\%), and 28-31 months (7.5\%). In Group B, most patients were born at $\geq 36$ weeks of gestation (83.7\%), followed by those born at $32-35$ weeks (16.3\%). We found that most patients in Group B were also born at full gestational age. None of the patients in Group B was born at 28-31 weeks of gestation.

More patients in Group A had a comorbidity (accompanying disease) (72.5\%) than those in Group B (67.4\%). All study participants had a normal birth weight ( $>2500$ g); $45 \%$ of Group A and $16.3 \%$ of Group B patients were born prematurely but had normal birth weight. One of the factors contributing to this is the food consumed by the mother during pregnancy. The demographic data revealed that in Group A, 67.5\% of the parents were private employees, $20 \%$ were entrepreneurs, and $12.5 \%$ were government employees. By contrast, in Group B, $67.4 \%$ parents were private employees, $18.6 \%$ were entrepreneurs, and $14 \%$ were government employees. The Kambang Hospital is affiliated to several insurance companies; therefore, many of the patients' parents used company insurance to pay for the treatment.

This study included neonates diagnosed with RDS. According to the Indonesian Doctor Association (Ikatan Dokter Indonesia) (2011) [3], RDS, also known as hyaline membrane disease (HMD), is a respiratory disorder caused by pulmonary immaturity and surfactant deficiency [4]. It usually develops in premature neonates born before 34 weeks of gestation and low birth weight neonates weighing $<1500 \mathrm{~g}$. Surfactants is formed at a gestational age of 24-28 weeks; therefore, the incidence of HMD is inversely proportional to the gestational age. The incidence rate of HMD is $60 \%$ in neonates born before 30 weeks of gestation, $25 \%$ in those born at 30-34 weeks, and 5\% in those born at 35-36 weeks. Other predisposing factors are maternal diabetes and cesarean delivery [4]

According to the patients' clinical weight data, the mean birth weight of the patients in Group A was $2.940 \pm 368.504 \mathrm{mg}$ and that of those in Group B was 3,131.40 $\pm 348.128 \mathrm{mg}$. Premature neonates formed the second largest majority in Group A. The average weight gain in neonates was 20-30 g/day after receiving parenteral nutrition for 1 day. This result was similar to that reported by the Indonesia Pediatric Society (Ikatan Dokter Anak Indonesia) [5]. When the neonates' condition improves, parenteral nutrition can be replaced by enteral nutrition (breast milk or formula milk). Prolonged consumption of high concentrations of parenteral nutrition can cause phlebitis.

Clinical parameters, including weight, blood glucose level, respiratory rate, pulse frequency, and body temperature of the neonates in both groups were assessed to compare the effectiveness of both the

Table 1: Basic characteristic of participants according to the treatment groups

\begin{tabular}{|c|c|c|c|}
\hline Parameters total (\%) & Preparation A n=40 (\%) & Preparation B $n=43(\%)$ & $\mathbf{p}$ \\
\hline \multicolumn{4}{|l|}{ Patient's age (days) } \\
\hline $1-14$ & $39(97.5)$ & 38 (88.4) & \multirow[t]{2}{*}{$0.109^{\mathrm{a}}$} \\
\hline $15-30$ & $1(2.5)$ & $5(11.6)$ & \\
\hline \multicolumn{4}{|l|}{ Pregnancy age (gestation) (weeks) } \\
\hline $28-31$ & $3(7.5)$ & $0(0)$ & \multirow[t]{3}{*}{$0.010^{\mathrm{b}}$} \\
\hline $32-35$ & $15(37.5)$ & 7 (16.3) & \\
\hline$\geq 36$ & $22(55)$ & $36(83.7)$ & \\
\hline \multicolumn{4}{|l|}{ Sex } \\
\hline Male & $20(50)$ & $24(55.8)$ & \multirow[t]{2}{*}{$0.596^{\mathrm{a}}$} \\
\hline Female & $20(50)$ & $19(44.2)$ & \\
\hline \multicolumn{4}{|l|}{ Comorbid } \\
\hline Hyperbilirubinemia/icterus/jaundice & $2(5)$ & $5(11.6)$ & \multirow[t]{3}{*}{$0.534^{\mathrm{b}}$} \\
\hline Neonatal infection/sepsis & $9(22.5)$ & $8(18.6)$ & \\
\hline Others & $29(72.5)$ & $29(69.8)$ & \\
\hline \multicolumn{4}{|l|}{ Social economic } \\
\hline Government employees & $5(12.5)$ & $6(14)$ & \multirow[t]{3}{*}{$0.973^{\mathrm{b}}$} \\
\hline Non-government employees (private employees) & $27(67.5)$ & $29(67.4)$ & \\
\hline Entrepreneur (farmer, other) & $8(20)$ & $8(18.6)$ & \\
\hline \multicolumn{4}{|l|}{ Insurance } \\
\hline BPJS & $18(45)$ & $17(39.5)$ & \multirow[t]{3}{*}{$0.418^{\mathrm{b}}$} \\
\hline Company & $1(2.5)$ & $4(9.3)$ & \\
\hline General & $21(52.5)$ & $22(51.2)$ & \\
\hline
\end{tabular}

${ }^{a}$ Analysis by Chi-square, banalysis by Fisher's exact test 
Table 2: Parameters of cost-effectiveness in each treatment group

\begin{tabular}{|c|c|c|c|}
\hline \multirow[t]{2}{*}{ Parameter } & \multicolumn{2}{|l|}{ Effectiveness (total [\%]) } & \multirow[t]{2}{*}{$\mathbf{p}$} \\
\hline & Preparation A $(n=40)$ & Preparation $B(n=43)$ & \\
\hline \multicolumn{4}{|l|}{ Weight (g) } \\
\hline Increasing weight gain & $28.48 \pm 3.464$ & $23.49 \pm 4.3$ & 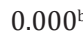 \\
\hline \multicolumn{4}{|l|}{ Blood glucose level (mg/dL) } \\
\hline Increasing blood glucose level & $26.72 \pm 7.841$ & $26.42 \pm 10.147$ & $0.879^{2}$ \\
\hline \multicolumn{4}{|l|}{ Respiratory rate (breaths/minute) } \\
\hline Returning to normal & $34(85)$ & $33(76.7)$ & $0.341^{c}$ \\
\hline Not returning to normal & $6(15)$ & $10(23.3)$ & \\
\hline \multicolumn{4}{|l|}{ Pulse $(\mathrm{x} /$ minute $)$} \\
\hline Returning to normal & $34(85)$ & $34(79.1)$ & $0.483^{\circ}$ \\
\hline Not returning to normal & $6(15)$ & $9(20.9)$ & \\
\hline \multicolumn{4}{|l|}{ Temperature $\left({ }^{\circ} \mathrm{C}\right)$} \\
\hline Returning to normal & $25(62.5)$ & $30(69.8)$ & $0.484^{\circ}$ \\
\hline Not returning to normal & $15(37.5)$ & $13(30.2)$ & \\
\hline
\end{tabular}

parenteral nutrition preparations. All of these are vital parameters that must be examined during a physical examination.

Table 2 shows that the effectiveness score of the increase in body weight was by 20-30 g/day and the blood glucose level ranged from 0 to $30 \mathrm{mg} / \mathrm{dL}$ in the neonates. Respiratory rate, pulse frequency, and body temperature were divided into two categories: Returning to normal and not returning to normal. The value for normal respiratory rate was 30-60 breaths/minute, that for normal pulse frequency was 100-160 breaths/minute, and that for normal body temperature was $36.5-37.5^{\circ} \mathrm{C}$. The data were assessed using the Chi-square test.

Participants and the clinical effectiveness ratio were determined using the values of average weight gain and blood glucose levels of the neonates. The effectivity scores of respiratory rate, pulse frequency, and body temperature were divided into "returning to normal" and "not returning to normal" categories.

The mean increase in the weight of the neonates in Group A was $28.48 \pm 3.464 \mathrm{~g} / \mathrm{d}$ and that in those belonging to Group B was $23.49 \pm 4.3 \mathrm{~g} /$ day. The mean blood glucose level in patients of Group A was $26.72 \pm 7.841 \mathrm{mg} / \mathrm{dL}$ and that of those in Group B was $26.42 \pm 10.147 \mathrm{mg} / \mathrm{dL}$. The respiratory rate and pulse frequency returned to normal in $85 \%$ patients of Group A and in $76.7 \%$ and $79.1 \%$ patients in Group B, respectively. Finally, the body temperature of $62.5 \%$ and $69.8 \%$ patients in Groups A and B, respectively, returned to normal.

Based on the data regarding clinical parameters of both the groups, the effectivity percentage for Group A was larger than that for Group B, although Group B had a higher sample size than Group A ( $\mathrm{n}=43$ [52\%] vs. $\mathrm{n}=40$ neonates [48\%]). RDS patients experience hypoglycemia; therefore, when the condition is left untreated, it could cause brain destruction and death. The mean weight of the neonates was $\geq 2500$ g, and $50 \%$ of them were born at full gestational age. This could be attributable to immature or improper functioning of their body organs, increasing the risk of hypoglycemia and other infections.

The data were assessed for normality; however, the data did not follow a normal distribution, except for the effectivity score of the increase in blood glucose level which appears to follow a normal distribution. The effectivity score of the increase in the blood glucose level was studied using parametric t-test methods. The Mann-Whitney U-test was used to study the effectivity score of the increase in the neonates' weight, respiratory rate, pulse frequency, and body temperature as these data were not normally distributed. Based on the results of the Mann-Whitney test, there was a significant difference between the effectivity score of the increase in neonates' weight $(20-30 \mathrm{~g} /$ day) (with $\mathrm{p}<0.05)$. Fisher's test also showed a statistically significant correlation between gestational age
Table 3: Parameters of the direct medical cost of participants based on treatment groups

\begin{tabular}{lll}
\hline \multirow{2}{*}{$\begin{array}{l}\text { Direct medical } \\
\text { cost types }\end{array}$} & Total cost (mean \pm SD) & \\
\cline { 2 - 3 } & Preparation A (n=40) & Preparation B (n=43) \\
\hline $\begin{array}{l}\text { Direct medical } \\
\text { cost }\end{array}$ & $458,290 \pm 23,828$ IDR & $408,347 \pm 19,728$ IDR \\
$\begin{array}{l}\text { Laboratory } \\
\text { examination cost }\end{array}$ & 125,000 IDR & 125,000 IDR \\
$\begin{array}{l}\text { Doctor visit cost } \\
\begin{array}{l}\text { Disposable } \\
\text { material cost }\end{array}\end{array}$ & $98,375 \pm 17,773$ IDR & $87,558 \pm 14,284$ IDR \\
$\begin{array}{l}\text { Room cost } \\
\text { Parenteral } \\
\text { nutrition cost }\end{array}$ & $107,375 \pm 11,435$ IDR & $101,744 \pm 10,112$ IDR \\
\hline
\end{tabular}

SD: Standard deviation

and type of parenteral nutrition preparation with pregnancy age score $(\mathrm{p}=0.010)$.

The direct medical cost data were also assessed for normal distribution; these data were normally distributed. Parametric tests were then used to study variables such as the pre- and posttreatment weight; the pre- and post-treatment pulse frequency; and direct medical cost components, including the costs for laboratory examination, doctor visit, room, and total direct medical cost. Parametric t-test showed that although there were differences in the average costs of some components, there were no significant differences in the laboratory examination cost $(p=0.474)$, doctor visit cost $(\mathrm{p}=0.648)$, room cost $(\mathrm{p}=0.629)$, and total direct medical cost $(\mathrm{p}=0.980)$ of the two groups.

The Mann-Whitney statistical test was employed to compare the difference in the costs of both the parenteral nutrition preparations. There were statistically significant differences between the costs of the two treatments $(\mathrm{p}=0.000)$. It can be concluded that there were significant differences in the gestational age, effectivity score of weight gain in infants, and parenteral nutrition costs between the two groups of parenteral nutrition preparations.

Based on direct medical cost data, the mean direct medical cost in Group A was higher (458.290 \pm 23.828 IDR) than that in Group B (408.347 \pm 19.728 IDR). This could be attributable to the parenteral nutrition preparations, which have a higher distribution and provision cost than conventional nutrition. Total direct medical cost for both preparations includes the cost of making the parenteral nutrition preparations, laboratory examination cost, disposable material cost, doctor visit cost, and room cost for the period 2013-2014. Parenteral 
nutrition cost was adjusted as per an annual inflation rate of $6 \%$. Other costs were not adjusted for inflation (Table 3).

Table 4 proves that parenteral nutrition involves a higher cost than conventional nutrition. Parenteral nutrition components are more complex than conventional nutrition components; therefore, they incur a higher cost for both, provision and distribution.

Sensitivity analysis showed that there was no difference with the base case. Preparation A (D10-CaGluconate) was part of the first quadrant, which had higher cost and higher effectivity. Meanwhile, preparation B (D5 1/4NS) was part of the third quadrant, which had lower cost with lower effectivity (Fig. 1). Sensitivity analysis with respect to effectivity change of preparation A and preparation B are shown in Table 5. Preparation A was the first choice because its effectivity level was greater than that of preparation B. However, preparation B could be a treatment alternative for RDS. Preparation A was more cost effective than preparation $\mathrm{B}$, with or without the $50 \%$ simulation of the increase and decrease in the effectivity costs of up to 3,359,194 IDR (decrease of $50 \%$ ) and 10,077,582 IDR (increase of 50\%) (Table 6). Table 7 shows the sensitivity analysis cost compared to the change in the direct medical cost, with or without the $1.5 \%$ simulation. Preparation A was also more costeffective in terms of the daily direct medical costs, with or without the $1.5 \%$ simulation of decrease of 9,866,951 IDR and increase of 10,167,468 IDR (Table 8). Total average cost-effectiveness ratio (ACER) score of the direct medical cost in each patient with preparation A from all effectivity was 6,791,720 IDR/effectivity. Meanwhile, in preparation B, the total cost was 23,789,458 IDR/effectivity. Therefore, the mean incremental cost-effectiveness ratio (ICER) direct medical cost of preparation B, compared to that of preparation A was 10,017,210 IDR. The ACER score of parenteral nutrition in each patient of Groups A and B from all

Table 4: Parameters of the direct medical cost of participants based on treatment groups

\begin{tabular}{lll}
\hline Costs & $\begin{array}{l}\text { Preparation } \\
\text { A (n=40) }\end{array}$ & $\begin{array}{l}\text { Preparation } \\
\text { B (n=43) }\end{array}$ \\
\hline Parenteral nutrition cost & $3,901,600$ IDR & $2,753,900$ IDR \\
Lowest & 92,850 IDR & 62,300 IDR \\
Highest & 99,550 IDR & 66,050 IDR \\
Laboratory examination cost & $5,000,000$ IDR & $5,375,000$ IDR \\
Disposable material cost & $1,200,000$ IDR & $1,290,000$ IDR \\
Doctor visit cost & $3,935,000$ IDR & $3,765,000$ IDR \\
Lowest & 70,000 IDR & 70,000 IDR \\
Highest & 150,000 IDR & 150,000 IDR \\
Perinatology room cost & $4,295,000$ IDR & $4,375,000$ IDR \\
Lowest & 100,000 IDR & 70,000 IDR \\
Highest & 125,000 IDR & 125,000 IDR \\
Total cost of all samples & $18,331,600$ IDR & $17,558,900$ IDR \\
Mean total cost for each patient & 458,290 IDR & 408,347 IDR \\
\hline
\end{tabular}

Table 5: Sensitivity analysis with respect to effectivity change

\begin{tabular}{lll}
\hline Effectivity & $\mathbf{- 5 0 \%}$ & $\mathbf{+ 5 0 \%}$ \\
\hline Weight (g) & & \\
$\quad$ Preparation A & 14.240 IDR & 42.720 IDR \\
$\quad$ Preparation B & 11.745 IDR & 35.235 IDR \\
Blood glucose level (mg/dL) & & \\
$\quad$ Preparation A & 13.365 IDR & 40.095 IDR \\
$\quad$ Preparation B & 13.21 IDR & 39.630 IDR \\
Respiratory rate (breaths/minute) & & \\
$\quad$ Preparation A & -6.175 IDR & -18.525 IDR \\
$\quad$ Preparation B & -3.885 IDR & -11.655 IDR \\
Pulse frequency ( $\times /$ minute) & & \\
$\quad$ Preparation A & -5.490 IDR & -16.470 IDR \\
$\quad$ Preparation B & -4.035 IDR & -12.105 IDR \\
Temperature ( $\left.{ }^{\circ} \mathrm{C}\right)$ & & \\
$\quad$ Preparation A & 0.0065 IDR & 0.0195 IDR \\
$\quad$ Preparation B & 0.0060 IDR & 0.0180 IDR \\
\hline
\end{tabular}

effectivity was 1,498,674 IDR/effectivity and 1,065,194 IDR/effectivity, respectively. Therefore, the mean ICER parenteral nutrition cost of preparation B compared to that of preparation A was 6,718,388 IDR. Table 9 shows the threshold analysis to the change of ICER score with the score of $3 \times$ gross domestic product (GDP) is US\$10,425.9.

\section{DISCUSSION}

Neonatal patients diagnosed with RDS tend to have a low blood sugar level or hypoglycemia. Thus, blood glucose levels must be closely monitored. Hypoglycemia occurs if the blood glucose level falls below $40 \mathrm{mg} \%$ (serum or plasma glucose $>10-15 \%$ ). This is probably caused by a defect in the glucose production, glucose overconsumption, or both. Low birth weight neonates; premature neonates; neonates with asphyxia or macrosomia; and neonates with signs of hypoglycemia must be examined in cases of hypoglycemia, especially if the oral nutrition consumption of the mother during pregnancy was poor. The normal blood glucose level of neonates is $50-80 \mathrm{mg} / \mathrm{dL}$. Delayed treatment may cause permanent brain damage, especially in low-weight and premature neonates. Chronic or recurring hypoglycemia can also affect

Table 6: Sensitivity analysis compared to the change in the ICER score effectivity

\begin{tabular}{|c|c|c|}
\hline ICER & $-50 \%$ & $+50 \%$ \\
\hline \multicolumn{3}{|l|}{ Weight (g) } \\
\hline Preparation B $\rightarrow$ A & 3.356 IDR & 10.069 IDR \\
\hline \multicolumn{3}{|l|}{ Blood glucose level (mg/dL) } \\
\hline Preparation $\mathrm{B} \rightarrow \mathrm{A}$ & 54.026 IDR & 162.077 IDR \\
\hline \multicolumn{3}{|c|}{ Respiratory rate (breaths/minute) } \\
\hline Preparation B $\rightarrow$ A & -3.657 IDR & -10.970 IDR \\
\hline \multicolumn{3}{|l|}{ Pulse frequency $(\times /$ minute $)$} \\
\hline Preparation $\mathrm{B} \rightarrow \mathrm{A}$ & -5.755 IDR & -17.266 IDR \\
\hline \multicolumn{3}{|l|}{ Temperature $\left({ }^{\circ} \mathrm{C}\right)$} \\
\hline Preparation $\mathrm{B} \rightarrow \mathrm{A}$ & $16,748,000$ IDR & $50,244,000$ IDR \\
\hline ICER preparation $\mathrm{B} \rightarrow \mathrm{A}$ & $16,795,970$ IDR & $50,387,910$ IDR \\
\hline Mean ICER & 3,359,194 IDR & $10,077,582$ IDR \\
\hline
\end{tabular}

Table 7: Sensitivity analysis cost compared to the change in the direct medical cost

\begin{tabular}{lll}
\hline $\begin{array}{l}\text { Treatment } \\
\text { groups }\end{array}$ & $\mathbf{- 1 . 5 \%}$ & $\mathbf{+ 1 . 5 \%}$ \\
\hline Preparation A & 451,416 IDR & 465,164 IDR \\
Preparation B & 402,222 IDR & 414,472 IDR \\
\hline
\end{tabular}

Table 8: Sensitivity analysis of the direct medical cost compared to the change in the ICER score of the direct medical cost

\begin{tabular}{lll}
\hline ICER & $\mathbf{- 1 . 5 \%}$ & $\mathbf{+ 1 . 5 \%}$ \\
\hline Preparation B $\rightarrow$ A & $9,866,951$ IDR & $10,167,468$ IDR \\
\hline ICER: Incremental cost-effectiveness ratio
\end{tabular}

Table 9: Threshold analysis to the change of the ICER score

\begin{tabular}{lll}
\hline ICER (effectivity) & $\begin{array}{l}\text { Treatment } \\
\text { groups }\end{array}$ & Direct medical cost \\
\hline $\begin{array}{l}\text { Preparation B } \rightarrow \mathrm{A} \\
\text { Weight }\end{array}$ & 10,009 IDR & $<$ US\$10,425.9/year \\
Blood glucose level & 161,107 IDR & $<$ US\$10,425.9/year \\
Respiratory rate & 10,905 IDR & $<$ US\$10,425.9/year \\
Pulse frequency & 17,163 IDR & $<$ US\$10,425.9/year \\
Temperature & 49,943,000 IDR & $<$ US $\$ 10.425 .9 /$ year \\
Threshold 3 $\times$ GDP & US\$10,425.9 & \\
ICER: Incremental cost-effectiveness ratio & \\
\hline
\end{tabular}




\begin{tabular}{|c|c|c|c|}
\hline \multicolumn{4}{|c|}{ Cost +} \\
\hline \multirow[t]{2}{*}{ Effectivity } & Domination & $\begin{array}{l}\text { ICER } \\
\text { (quadrant I) } \\
\text { D10- } \\
\text { CaGluconate }\end{array}$ & \multirow{2}{*}{$\begin{array}{l}\text { Effectivity + } \\
\text { Dominant }\end{array}$} \\
\hline & $\begin{array}{c}\text { ICER } \\
\text { (quadrant III) } \\
\text { D5 } 1 / 4 \mathrm{NS}\end{array}$ & & \\
\hline
\end{tabular}

Fig. 1: The cost effectivity of the D10-CaGluconate and D5 1/4NS preparations. ICER: Incremental cost-effectiveness ratio

the development and function of the brain. When accompanied by ischemia and hypoxemia, hypoglycemia may cause permanent brain damage [6].

RDS has signs or symptoms as parameters for the diagnosis which must be treated. Respiratory distress is recognized as any signs of breathing difficulties in neonates [7]. Respiratory rate is one of the main parameters in the diagnosis of RDS. Patients who experience difficulty in breathing or cannot breathe must be treated immediately, otherwise it may lead to death. The second parameter is pulse frequency. RDS patients tend to experience tachycardia. When such a patient is not treated immediately, it could cause heart failure. The third parameter is body temperature. RDS patients have a high risk of hypothermia; thus, lighting with ultraviolet light or other warming methods must be done for treatment. All these conditions (apnea, tachycardia, and hypothermia) must be treated immediately to avoid permanent damage to the brain, paralysis, and death. Intensive care is crucial. The previous study showed that RDS occurs in $78 \%$ of neonates weighing 501 $1500 \mathrm{~g}$, with $71 \%$ cases reported in neonates weighing 501-750 g, 54\% in neonates weighing 751-1000 g, 36\% in those weighing 1001-1250 g, and $26 \%$ in those weighing $1250-1500 \mathrm{~g}$ [8-11]. A study conducted by Gunn et al. suggested that infants with respiratory distress who weigh $<1500 \mathrm{~g}$ may receive the greater benefit from total parenteral nutrition [12].

According to the previous studies [13], the values of the cost incurred in health programs must be adjusted each year, by $3.5 \%$ in England and $4 \%$ in France. Both countries need sensitivity analysis using alternative discounted medical cost $1.5 \%$ in England; 3\% and 6\% in France). In France, after 30 years, the discounted medical cost should be progressively decreased by $2 \%$. The National Institute for Clinical Excellence (NICE) has set the lowest price or discounting for each therapy with long-term medical benefit at $1.5 \%$. Therefore, simulation of the increase and decrease in the cost by $50 \%$ is used for effectivity. In this study, the author used the adjustment score suggested by NICE (1.5\%). Indonesia, as a developing country, does not have its own established sensitivity score cost. Previous studies have recommended simulation scores of $5 \%, 15 \%$, and $20 \%$ for the simulation of the increased and decreased costs.

As per our knowledge, no previous study has conducted a costeffectiveness analysis between parenteral D10-CaGluconate and conventional D5 1/4NS nutrition preparations. If there were two or more medical interventions with the same purpose but different levels of effectiveness, cost-effectiveness would be the deciding factor for selecting the method. Based on threshold analysis, we can conclude that the cost incurred for RDS patients was relatively under the GDP. In other words, it was still suitable with medication rationality. This retrospective cohort research used 83 samples, including 40 D10CaGluconate samples and 43 D5 $1 / 4 \mathrm{NS}$ samples. The following secondary data used in this research were obtained from the patients' medical records: Neonates weight, blood glucose level, respiratory rate, pulse frequency, body temperature, and medical cost. It was found that the patients' diseases were not homogenous and had severe variations; in addition, there were some non-specific diagnoses. The significance of the statistical test was low due to its weak power. Advanced studies need to be conducted to evaluate the effect of bias factors on the effectiveness of the preparation.

\section{CONCLUSION}

The D10-CaGluconate preparation was more cost-effective than the D5 1/4NS preparation. However, the D5 1/4NS preparation could serve as an alternative treatment for RDS in normal-weight neonatal patients. To conclude, further studies on parenteral nutrition that involve more complex parenteral preparations need to be conducted to determine the actual effectiveness of a parenteral nutrition preparation.

\section{REFERENCES}

1. Ministry of Health Republic of Indonesia. Pedoman Penerapan Kajian Farmakoekonomi. Jakarta: Jenderal Bina Pelayanan Kefarmasian dan Alat Kesehatan Ministry of Health Republic of Indonesia; 2013.

2. Murray CJ, Knaul F, Musgrove P, Xu K, Kawabata K. Defining and Measuring Fairness in Financial Contribution to the Health System. Geneva: World Health Organization; 2001

3. Ikatan Dokter Anak Indonesia. Pedoman Pelayanan Medis. Edisi II. Jakarta: Ikatan Dokter Anak Indonesia; 2011.

4. Hermansen CL, Lorah KN. Respiratory distress in the newborn. Am Fam Physician 2007;76(7):987-4.

5. Kosim MS. Buku Ajar Neonatalogi. Jakarta: IDAI; 2009.

6. Baron RB. Nutrition. In: Tierney LM, McPhee SI, Papadakis MA, editors. Current Medical Diagnosis and Treatment. New York: McGraw Hill; 2007.

7. Edwards MO, Kotecha SJ, Kotecha S. Respiratory distress of the term newborn infant. Paediatr Respir Rev 2013;14(1):29-36; quiz 36-7.

8. Frankel LR. Respiratory distress and failure. In: Kliegman R, Behrmanq R, Jenson H, Stanton B, editors. Nelson Textbook of Pediatrics. $18^{\text {th }}$ ed. Philadelphia, PA: Sunders Elsevier; 2007. p. 421-4.

9. Fanaroff AA, Stoll BJ, Wright LL, Carlo WA, Ehrenkranz RA, Stark AR, et al. Trends in neonatal morbidity and mortality for very low birth weight infants. Am J Obstet Gynecol 2007;196(2):147. e1-8.

10. Kusuda S, Fujimura M, Uchiyama A, Totsu S, Matsunami K. Neonatal research network, Japan. Trends in morbidity and mortality among very-low-birth-weight infants from 2003 to 2008 in Japan. Pediatr Res 2012;72(5):531-8.

11. Isayama T, Lee SK, Mori R, Kusuda S, Fujimura M, Ye XY, et al. Comparison of mortality and morbidity of very low birth weight infants between Canada and Japan. Pediatrics 2012;130(4):e957-65.

12. Gunn T, Reaman G, Outerbridge EW, Colle E. Peripheral total parenteral nutrition for premature infants with the respiratory distress syndrome: A controlled study. J Pediatr 1978;92(4):608-13.

13. Massetti M, Aballéa S, Videau Y, Rémuzat C, Roïz J, Toumi M. A comparison of HAS \& NICE guidelines for the economic evaluation of health technologies in the context of their respective national health care systems and cultural environments. J Mark Access Health Policy 2015;3:1-10 